Article

\title{
Synthesis Mechanism of an Environment-Friendly Sodium Lignosulfonate/Chitosan Medium-Density Fiberboard Adhesive and Response of Bonding Performance to Synthesis Mechanism
}

\author{
Xiaodi Ji ${ }^{1, *} \mathbb{0}$, Minghui Guo ${ }^{2}$, Li Zhu ${ }^{3}$, Wenxin Du ${ }^{2}$ and Hongbin Wang ${ }^{1}$ \\ 1 College of Forestry, Northwest A\&F University, Yangling 712100, China; yanglinwhb@nwsuaf.edu.cn \\ 2 Key Lab of Bio-Based Material Science and Technology of Ministry of Education, Material Science and \\ Engineering College, Northeast Forestry University, Harbin 150040, China; gmh1964@126.com (M.G.); \\ nefudwx@hotmail.com (W.D.) \\ 3 Network and Education Center, Yangling Vocational and Technical College, Yangling 712100, China; \\ katrina123789@163.com \\ * Correspondence: mingduzhiwang@163.com
}

Received: 31 October 2020; Accepted: 11 December 2020; Published: 14 December 2020

\begin{abstract}
Environment-friendly medium-density fiberboards (MDFs) prepared using sodium lignosulfonate/chitosan adhesives $(\mathrm{L} / \mathrm{C})$ show potential in environment-friendly wood-based panel application. However, the synthesis mechanism of this adhesive and the relationships between synthesis mechanism and bonding performance were not discussed in depth. Herein, the synthesis mechanism of $\mathrm{L} / \mathrm{C}$ was explored in detail based on characterizations of $\mathrm{L} / \mathrm{C}$ with different mass ratios of sodium lignosulfonate to chitosan by Fourier-transform infrared spectroscopy, thermogravimetric analysis, and X-ray diffraction. For L/C with different mass ratios of sodium lignosulfonate to chitosan, the corresponding bonding performance was also determined based on characterizations of mechanical and dimensional performance of MDFs. Results showed a 3D network structure of $\mathrm{L} / \mathrm{C}$ formed through the hydrogen linkages among hydroxyl groups in sodium lignosulfonate and hydroxyl and amino groups in chitosan, amide linkages resulted from reaction between carbonyl groups in sodium lignosulfonate and amino groups in chitosan, and sulfonamide linkages originated from reaction between sulfonic groups in sodium lignosulfonate and amino groups in chitosan. The mechanical performance of MDF was closely related to the 3D network and amino groups of $\mathrm{L} / \mathrm{C}$, while the dimensional performance of MDF was negatively affected by sodium lignosulfonate. The MDFs with 1:3 and 1:2 mass ratios of sodium lignosulfonate to chitosan showed superior mechanical properties and comparable dimensional performance with a commercial panel.
\end{abstract}

Keywords: MDF adhesive; chitosan; sodium lignosulfonate; synthesis mechanism; bonding performance; chemical structure; thermal stability; crystalline structure

\section{Introduction}

Traditional medium-density fiberboards (MDFs) on the market are prepared mainly using formaldehyde-containing adhesives, which causes harm to humans and the environment and further hinders the high-end applications of MDF [1]. Furthermore, these formaldehyde-containing adhesives are made synthetically from non-renewable and non-replenishable petrochemical resources. With the depletion of petrochemical resources, the deterioration of raw materials for synthetic resin has also been becoming an issue of concern. In contrast to these synthetic adhesives, biopolymer-based MDF adhesives, such as soy protein [2], wheat protein, [3] and starch [4], have gained more attention in 
recent decades, due to their characteristic eco-friendliness and renewability [5]. However, the high costs of these materials and their relatively complicated manufacturing processes along with their poor bonding strengths and water resistances have limited their industrial applications. Recently, chitosan has been recognized world-wide as a potential biopolymer-based wood adhesive, because of its non-toxicity and renewability, which is of great interest to both industries and consumers [6]. Chitosan is a carbohydrate polymer comprising of $\beta$-(1,4)-linked 2-acetamido-2-deoxy-D-glucopyranose and 2-amino-2-deoxy-D-glucopyranose units. It is obtained by deacetylation of chitin, which is present as the main structural element of crustacean shells, insect exoskeletons, fungal cell walls, microfauna, and plankton. It is the second most abundant natural polysaccharide, next to only cellulose [7]. Like other traditional amino resin adhesives (e.g., urea-formaldehyde resins and melamine resins), chitosan has reactive amino side groups and hence, it can provide strong adhesion between suitable adherend-like biomass materials [8]. Moreover, use of chitosan along with other hydrophilic polymers can reduce their water affinity due to the formation of hydrogen bonds between their hydrophilic groups [9]. Owing to its anti-microbial properties, chitosan also acts as an environment-friendly preservative [10]. Therefore, chitosan has great potential as an adhesive with multifunctional properties for MDFs.

However, the high cost of chitosan as a wood adhesive restricts its large-scale applications. Hence, blending of chitosan with other low-cost biopolymers is a promising way to reduce its cost. Lignin is one of the most abundant natural polymers, which fills up the voids present in the wood cell wall and bonds together cellulose, hemicellulose, and abutting wood cells. As with traditional phenolic resins, lignin has a three-dimensional polymeric network and many phenolic hydroxyl groups, showing great potential as a cheap, natural MDF adhesive. Lignosulfonate is a lignin derivative, which results from the incorporation of sulfonate groups $\left(\mathrm{SO}_{3}{ }^{-}\right)$into the benzylic carbon of the phenylpropane units of lignin, during the sulfite pulping process [11]. Currently, most lignosulfonate is burned as fuel, which is not only a waste of resources, but also leads to a series of environmental and health problems. Reutilization of lignosulfonate will reduce the amount of the biowaste and add value to lignosulfonate. There are many reactive groups in lignosulfonate, such as sulfonic groups, methoxy groups, hydroxyl groups, carbonyl groups, and phenolic hydroxyl groups, making it an anionic polyelectrolyte that is extremely soluble in water. These reactive groups in lignosulfonate enable it to undergo a variety of chemical reactions, such as sulfonation, oxidation, phenolation, polycondensation, and graft copolymerization. Lately, lignin has found applications as wood adhesives [12-16]. However, lignosulfonate cannot be directly used as an MDF adhesive because of its poor bonding strength and water resistance [17].

Recently, chitosan-lignin blends have been researched for their role in removal of water pollutants, wound dressing, controlled drug delivery, food packaging, and bonding of wood materials [18-22]. In our earlier work [23], the development of lignosulfonate/chitosan adhesives (L/C) as potential cheap and environment-friendly MDF adhesives was presented. The mass ratio of lignosulfonate to chitosan and adhesive amount were preliminary optimized in that work. However, the potential synthesis mechanism of that adhesive was not deeply investigated. The response of bonding performance to synthesis mechanism were not evenly discussed. Therefore, in this study, the synthesis mechanism of $\mathrm{L} / \mathrm{C}$ was investigated in detail based on characterizations of chemical structure, thermal stability, and crystalline structure of $\mathrm{L} / \mathrm{C}$ with different mass ratios of lignosulfonate to chitosan. The bonding performance of $\mathrm{L} / \mathrm{C}$ with corresponding mass ratios of lignosulfonate to chitosan was also determined based on characterizations of mechanical and dimensional performance of corresponding MDFs to analyze the response of bonding performance to synthesis mechanism.

\section{Materials and Methods}

\subsection{Materials}

Chitosan (CAS No. 9012-76-4) was provided by Sun Chemical Technology Co. (Shanghai, China). Its deacetylation degree was more than $95 \%$ and its molecular weight was between 100,000 to 150,000 Da. 
Glacial acetic acid $\left(\mathrm{CH}_{3} \mathrm{COOH}\right.$, CAS No. 64-19-7, AR) was supplied by Harbin Kaimeisi Technology Co. (Harbin, China). Sodium lignosulfonate (CAS No. 8061-51-6) was purchased from Wuhan East China Chemical Co. (Wuhan, China). Its sulfonation degree was $1.42 \mathrm{mmol} / \mathrm{g}$. Water distilled in our lab was used for all the experiments. All chemicals were used as received without further purification. Miscellaneous wood fibers (20-80 mesh) comprising a blend of softwood and hardwood fibers from different species including Larix gmelinii, Pinus koraiensis, and Populus davidiana and containing cellulose $(46.70 \mathrm{wt} \%)$, hemicellulose $(29.17 \mathrm{wt} \%)$, and lignin $(22.39 \mathrm{wt} \%)$ were provided by Greater Khingan Range Hengyou Furniture Co. Ltd. (Great Khingan, Foshan, China). The wood fibers were produced by a fiber hot grinding process and dried in an oven at $80^{\circ} \mathrm{C}$ to reduce the moisture content from $18 \%$ to about $6 \%$. The control group was a commercial MDF with density of $0.8 \mathrm{~g} / \mathrm{cm}^{3}$ and thickness of $5 \mathrm{~mm}$ purchased from Oasis Forestry Industry Co. (Suzhou, China).

\subsection{Synthesis of $L / C$}

The L/C was synthesized as follows: firstly, chitosan powder and sodium lignosulfonate powder were mixed evenly after being stirred with a rod for a few minutes. Then, an appropriate amount of distilled water was poured into the beaker. The sodium lignosulfonate powder was dissolved immediately and the chitosan powder was dispersed in the sodium lignosulfonate solution. Next, glacial acetic acid solution was dumped into the beaker containing chitosan and sodium lignosulfonate. Finally, the chitosan was completely dissolved and a uniform brown viscous solution was obtained after rapid stirring for 10 to $20 \mathrm{~min}$. The above operations were all carried out at room temperature. The mass ratios of sodium lignosulfonate to chitosan in L/C were 1:0, 3:1, 2:1, 1:1, 1:2, 1:3, and 0:1, respectively. The mass ratio of glacial acetic acid to chitosan was $2: 3$ and the mass ratio of chitosan to distilled water was $3 \%$.

\subsection{MDF Preparation}

The preparation of MDF was as follows: first, the wood fibers were put in a high-speed mixer (SHR-10A, Zhangjiagang Tongsha Plastic Machinery Co., Zhangjiagang, China). Then, the newly-synthesized $\mathrm{L} / \mathrm{C}$ was poured into the mixture at an adhesive to wood fiber mass ratio of $4 \%$ and stirred at $750 \mathrm{r} / \mathrm{min}$ for $5 \mathrm{~min}$. Then, the mixture was collected and dried at room temperature until the moisture content dropped to $20 \%$. Thereafter, the mixture was manually spread into a $250 \mathrm{~mm} \times 250 \mathrm{~mm}$ forming box and pre-pressed at $1.0 \mathrm{MPa}$ for $1 \mathrm{~min}$ to form a slab. Next, the pre-pressed slab was placed between two parallel plane plates $(400 \mathrm{~mm} \times 400 \mathrm{~mm})$ of a hot press (Harbin Dongda Wood-based Panel Machinery Manufacturing Co., Harbin, China) and compressed at $170{ }^{\circ} \mathrm{C}$ for $480 \mathrm{~s}$ employing a pre-programmed process (Figure 1). Finally, the edges were trimmed to obtain the final board size and density of $220 \mathrm{~mm} \times 220 \mathrm{~mm} \times 5 \mathrm{~mm}$ and $0.8 \pm 0.02 \mathrm{~g} \mathrm{~cm}^{-3}$, respectively. Before the performance test described in the following chapters, MDF was conditioned for 2 days at $40 \%$ relative humidity and room temperature.

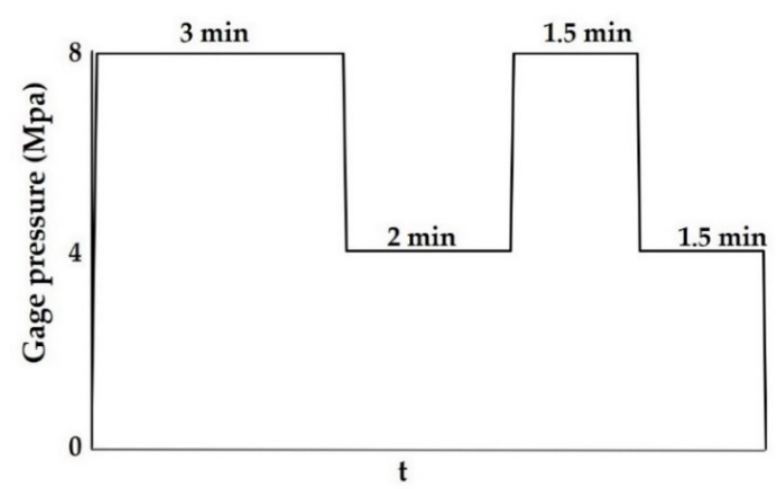

Figure 1. Pre-programmed schedule for hot-pressing process. 


\subsection{Synthesis Mechanism Analysis}

In order to understand the synthesis mechanism of $\mathrm{L} / \mathrm{C}$, the chemical structure, thermal stability, and crystalline structure of L/C were characterized. Fourier-transform infrared (FTIR) spectroscopy (ThermoFisher, Waltham, MA, USA) was used to analyze the functional groups in chitosan, sodium lignosulfonate, and L/C with a Nicolet Magna-IR560 E.S.P. using KBr method, in the spectral range of 650 to $4000 \mathrm{~cm}^{-1}$. The spectra were recorded with a resolution of $4 \mathrm{~cm}^{-1}$ by accumulating 32 scans. X-ray diffraction (XRD) patterns of chitosan, sodium lignosulfonate, and L/C were collected with a Rigaku D/max 2200 X-ray diffractometer (Rigaku, Tokyo, Japan). The X-ray diffractometer used a $\mathrm{Cu} \mathrm{K} \alpha$ radiation source and its scan rate was set to $4^{\circ} \mathrm{min}^{-1}$. It works at $40 \mathrm{kV}$ and $30 \mathrm{~mA}$, in the $2 \theta$ range of $5-40^{\circ}$. The thermal stabilities of chitosan, sodium lignosulfonate, and $\mathrm{L} / \mathrm{C}$ were measured with a NET-ZSCH-TGA209 thermogravimetric analyzer (NETZSCH, Selb, Germany). The samples (5 mg each in a $70 \mu \mathrm{L}$ alumina pan) were heated from $40{ }^{\circ} \mathrm{C}$ to $800{ }^{\circ} \mathrm{C}$ at $10^{\circ} \mathrm{C} / \mathrm{min}$ and $30 \mathrm{~mL} / \mathrm{min}$ nitrogen flow rates.

\subsection{Bonding Performance Test}

The bonding performance of $\mathrm{L} / \mathrm{C}$ could be evaluated from mechanical and dimensional properties of MDFs, which were determined according to the Chinese national standard GB/T 17657-2013. A general mechanical testing machine (CMT5504, Shenzhen Xinsansi Co., Shenzhen, China) was used to evaluate its internal bond strength (IB), modulus of rupture (MOR), and modulus of elasticity (MOE). IB is the ratio of the maximum damage tension perpendicular to the sample surface to the sample area. The low-density surface area of the MDF sample $(50 \mathrm{~mm} \times 50 \mathrm{~mm})$ used for IB measurement was polished to improve the surface finish, and then both sides of the sample were glued to steel fixtures with hot melting adhesive. The specimen was pulled apart in the vertical direction using a tensile load to each steel fixture at a crosshead speed of $0.5 \mathrm{~mm} / \mathrm{min}$ until the specimen failed. MOR is the ratio of the bending moment to the bending modulus under the maximum load, and MOE is the stress-strain ratio generated by the load within the elastic limit of the MDF. MOR and MOE were measured by performing a three-point static bending test on a sample $(200 \mathrm{~mm} \times 50 \mathrm{~mm})$ at a speed of $5 \mathrm{~mm} / \mathrm{min}$. The dimensional characteristics were determined by the thickness swell (TS) measurement, which is the percentage increase in thickness of the sample $(50 \mathrm{~mm} \times 50 \mathrm{~mm})$ after being immersed in water at room temperature for $24 \mathrm{~h}$. The thickness of the sample was measured before and immediately after immersion for $24 \mathrm{~h}$. The MOR and MOE tests were repeated 12 times, and the IB and TS measurements were repeated 8 times to obtain an average value.

\section{Results and Discussion}

\subsection{FTIR Analysis}

The FTIR spectra of chitosan, sodium lignosulfonate, and L/C are shown in Figure 2. The main peaks in the FTIR spectrum of chitosan were assigned as follows: $3354 \mathrm{~cm}^{-1}$ (NH stretching vibrations of the $-\mathrm{NH}_{2}$ in primary amines), $3291 \mathrm{~cm}^{-1}\left(-\mathrm{NH}_{2}\right.$ stretching vibrations), from 3600 to $3000 \mathrm{~cm}^{-1}$ (overlapping of $-\mathrm{OH}$ stretching vibrations and $-\mathrm{NH}_{2}$ stretching vibrations), $2929 \mathrm{~cm}^{-1}$ ( $-\mathrm{CH}_{2}$ asymmetric stretching vibrations), $2866 \mathrm{~cm}^{-1}$ (symmetric stretching vibrations), $1650 \mathrm{~cm}^{-1}$ (C=O stretching vibrations of amide I band), $1590 \mathrm{~cm}^{-1}$ ( $\mathrm{NH}_{2}$ in amino group), $1549 \mathrm{~cm}^{-1}$ (amide II band, $-\mathrm{CN}$ stretching vibrations in acetylated groups), $1411 \mathrm{~cm}^{-1}\left(-\mathrm{CH}_{2}\right.$ bending vibrations), $1372 \mathrm{~cm}^{-1}$ (- $\mathrm{CH}_{3}$ symmetrical deformations in amide groups), $1317 \mathrm{~cm}^{-1}$ (CN stretching vibrations of amide III band), $1253 \mathrm{~cm}^{-1}$ (amide III band, $-\mathrm{NH}$ stretching vibrations), $1155 \mathrm{~cm}^{-1}$ (ether bond, $\mathrm{C}-\mathrm{O}-\mathrm{C}$ bending vibrations), $1058 \mathrm{~cm}^{-1}$ (C-O stretching vibrations in $\mathrm{C}-\mathrm{O}-\mathrm{C}$ rings), $1019 \mathrm{~cm}^{-1}$ (C-O stretching vibrations in $\mathrm{C}-\mathrm{O}-\mathrm{C}$ rings), and $859 \mathrm{~cm}^{-1}$ ( $\beta-1,4$-glycosidic bond) [24-28]. Peaks in the spectrum of sodium lignosulfonate were as follows: $3252 \mathrm{~cm}^{-1}$ (-OH stretching vibrations), $2967 \mathrm{~cm}^{-1}$ and $2931 \mathrm{~cm}^{-1}$ (-CH symmetric stretching vibrations), $1585 \mathrm{~cm}^{-1}$ and $1413 \mathrm{~cm}^{-1}$ (stretching vibrations of aromatic skeleton), $1119 \mathrm{~cm}^{-1}, 878 \mathrm{~cm}^{-1}$, and $770 \mathrm{~cm}^{-1}$ (guaiacyl unit, bending vibrations), $1046 \mathrm{~cm}^{-1}$ 
( $\mathrm{S}=\mathrm{O}$ symmetric stretching of the $-\mathrm{SO}_{3}$ groups) and $973 \mathrm{~cm}^{-1}$ (out-plane bending vibrations of aromatic skeleton) [28-30].

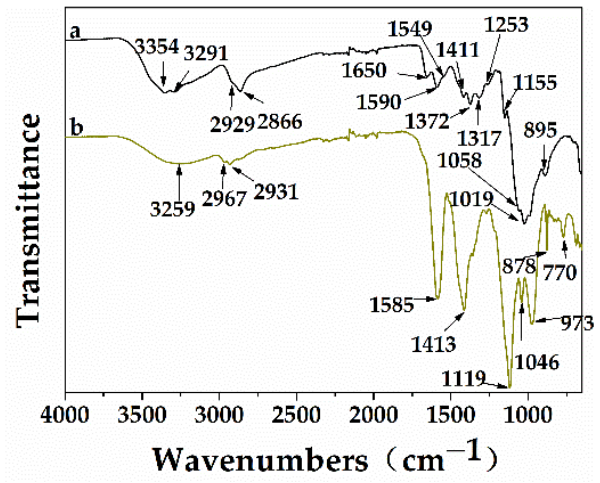

(A)

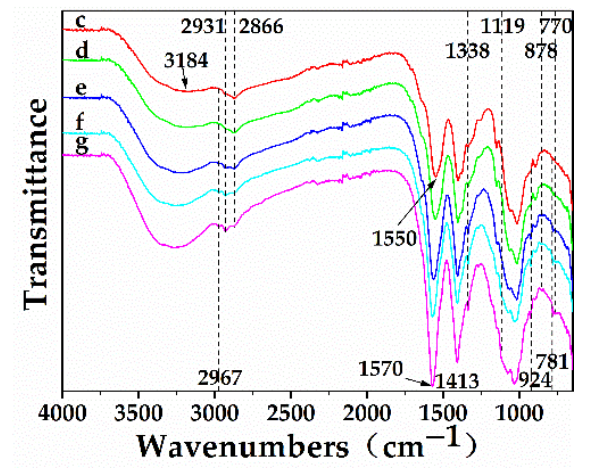

(B)

Figure 2. (A) FTIR spectra of (a) chitosan and (b) sodium lignosulfonate; (B) FTIR spectra of sodium lignosulfonate/chitosan adhesives $(\mathrm{L} / \mathrm{C})$ with different mass ratios of sodium lignosulfonate to chitosan: (c) $1: 3$, (d) $1: 2$, (e) 1:1, (f) 2:1, and (g) 3:1.

The FTIR spectra of L/C showed some major differences when compared with those of chitosan and sodium lignosulfonate. Two separate peaks at $3354 \mathrm{~cm}^{-1}$ and $3291 \mathrm{~cm}^{-1}$ and one peak at $3252 \mathrm{~cm}^{-1}$ were no longer visible, because a single broad peak appeared in the FTIR spectra of L/C. The broad band was shifted to $3184 \mathrm{~cm}^{-1}$ in the FTIR spectrum of L/C with a 1:3 mass ratio of sodium lignosulfonate to chitosan, i.e., red shift occurred. This was attributed to the newly formed intramolecular and intermolecular hydrogen bonds among hydroxyl groups in sodium lignosulfonate and hydroxyl groups and amino groups in chitosan. This band gradually shifted to higher wavenumbers with an increase in the sodium lignosulfonate amount in $\mathrm{L} / \mathrm{C}$, due to the fact that the number of hydroxyl groups in sodium lignosulfonate was lower than the number of amino and hydroxyl groups in chitosan, which resulted in lower numbers of hydrogen bonds formed among hydroxyl groups in sodium lignosulfonate and hydroxyl groups and amino groups in chitosan. As the amount of sodium lignosulfonate in L/C increased, the following changes were also observed: an increase in intensities of $2967 \mathrm{~cm}^{-1}$ and $2931 \mathrm{~cm}^{-1}$ peaks, a decrease in intensity of the peak at $2866 \mathrm{~cm}^{-1}$, a gradual increase in the intensity of the peak at $1413 \mathrm{~cm}^{-1}$ (stretching vibrations of the aromatic skeleton), a sharp increase in the intensities of the $1119 \mathrm{~cm}^{-1}, 878 \mathrm{~cm}^{-1}$, and $770 \mathrm{~cm}^{-1}$ peaks (bending vibrations of guaiacyl unit). Moreover, two peaks at $1590 \mathrm{~cm}^{-1}$ and $1549 \mathrm{~cm}^{-1}$ and one peak at $1585 \mathrm{~cm}^{-1}$ were no longer visible, while a sharp peak between $1570 \mathrm{~cm}^{-1}$ and $1550 \mathrm{~cm}^{-1}$ appeared in L/C. This peak seemed to be a simple overlapping of the peak at $1585 \mathrm{~cm}^{-1}$ corresponding to stretching vibrations of the aromatic skeleton, the peak at $1590 \mathrm{~cm}^{-1}$ corresponding to $\mathrm{NH}_{2}$ in amino groups, and the peak at $1549 \mathrm{~cm}^{-1}$ corresponding to $\mathrm{CN}$ stretching vibrations in the amide II band. However, in the FTIR spectrum of $\mathrm{L} / \mathrm{C}$ with a 1:3 mass ratio of sodium lignosulfonate to chitosan, this peak was at $1550 \mathrm{~cm}^{-1}$, which was in close proximity to the peak at $1549 \mathrm{~cm}^{-1}$ corresponding to $\mathrm{CN}$ stretching vibrations in the amide II band, indicating that amide bonds might form as a result of the reaction of carbonyl groups of sodium lignosulfonate and amino groups of chitosan. This peak gradually shifted to higher wavenumbers and got closer to the peak at $1585 \mathrm{~cm}^{-1}$ corresponding to stretching vibrations of the aromatic skeleton with an increase in sodium lignosulfonate content in $\mathrm{L} / \mathrm{C}$, due to the increasing numbers of aromatics in $\mathrm{L} / \mathrm{C}$. A new peak appeared in the spectra of $\mathrm{L} / \mathrm{C}$ at $924 \mathrm{~cm}^{-1}$, which was absent in the spectra of chitosan and sodium lignosulfonate. This peak was assigned to the characteristic amide bond (CO-NH) $[31,32]$. This confirmed that amide bonds were formed due to the reaction of carbonyl groups of sodium lignosulfonate and amino groups of chitosan. Additionally, two new peaks also appeared in the FTIR spectra of the L/C at $1338 \mathrm{~cm}^{-1}$ and $781 \mathrm{~cm}^{-1}$, which corresponded to characteristic peaks of 
sulfonamide groups ( $\mathrm{S}=\mathrm{O}$ and $\mathrm{S}-\mathrm{N}$, respectively) [33-35]. This suggested that the sulfonic groups in sodium lignosulfonate reacted with the amino groups in chitosan to form sulfonamide groups. The intensities of the peaks at $1338 \mathrm{~cm}^{-1}(\mathrm{~S}=\mathrm{O}), 781 \mathrm{~cm}^{-1}(\mathrm{~S}-\mathrm{N})$, and $924 \mathrm{~cm}^{-1}(\mathrm{CO}-\mathrm{NH})$ increased with an increase in the sodium lignosulfonate content of $\mathrm{L} / \mathrm{C}$.

Chitosan is a linear polymer, while sodium lignosulfonate is a three-dimensional polymeric network. The chemical connection between chitosan and sodium lignosulfonate is the result of the reaction between carbonyl groups and sulfonamide groups in sodium lignosulfonate and amino groups in chitosan. Hence, it can be speculated that L/C could have a 3D network structure.

\subsection{Thermal Analysis}

The thermogravimetric (TG) and derivative TG (DTG) curves of chitosan, sodium lignosulfonate, and L/C are shown in Figure 3 and the results are presented in Table 1 . It can be clearly seen from Figure 4 and Table 1 that the first step of weight loss occurred in the temperature range of $40-100{ }^{\circ} \mathrm{C}$, in which chitosan, sodium lignosulfonate, and L/C lost water molecules.

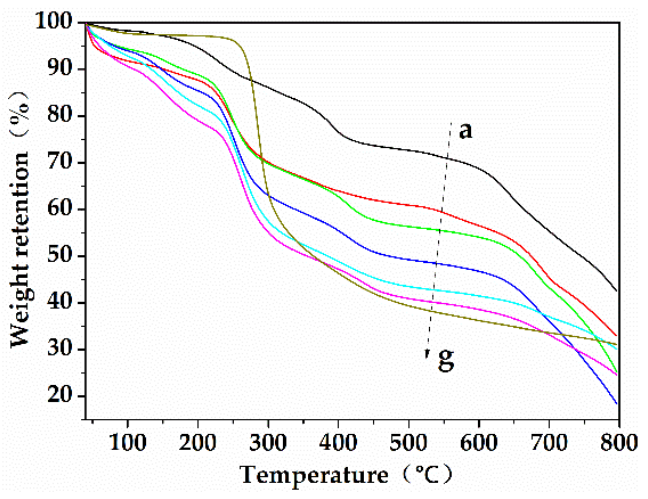

(A)

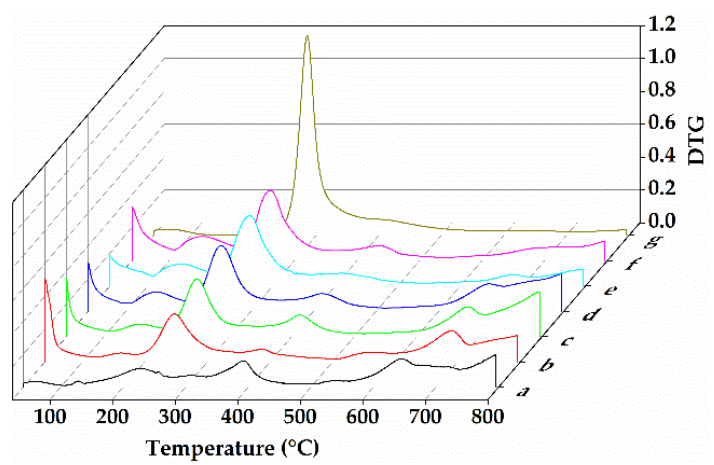

(B)

Figure 3. TG (A) and DTG (B) curves of (a) sodium lignosulfonate, L/C with different mass ratios of sodium lignosulfonate to chitosan: (b) 3:1, (c) 2:1, (d) 1:1, (e) 1:2, (f) 1:3, and (g) chitosan.

Table 1. Results of TG-DTG curves of (a) sodium lignosulfonate, $\mathrm{L} / \mathrm{C}$ with different mass ratios of sodium lignosulfonate to chitosan: (b) 3:1, (c) 2:1, (d) 1:1, (e) 1:2, (f) 1:3, and (g) chitosan.

\begin{tabular}{|c|c|c|c|c|c|c|c|}
\hline \multirow{2}{*}{ Sample } & \multicolumn{2}{|c|}{ Stage A } & \multicolumn{2}{|c|}{ Stage B } & \multicolumn{2}{|c|}{ Stage C } & \multirow{2}{*}{$\begin{array}{c}\text { Residual } \\
\text { Amount after } \\
800{ }^{\circ} \mathrm{C}(\%)\end{array}$} \\
\hline & $\begin{array}{c}\text { Temperature } \\
\left({ }^{\circ} \mathrm{C}\right)\end{array}$ & $\begin{array}{l}\text { Weight } \\
\text { Loss (\%) }\end{array}$ & $\begin{array}{c}\text { Temperature } \\
\left({ }^{\circ} \mathrm{C}\right)\end{array}$ & $\begin{array}{l}\text { Weight } \\
\text { Loss (\%) }\end{array}$ & $\begin{array}{c}\text { Temperature } \\
\left({ }^{\circ} \mathrm{C}\right)\end{array}$ & $\begin{array}{l}\text { Weight } \\
\text { Loss (\%) }\end{array}$ & \\
\hline a & 128 & 0.70 & 228 & 8.16 & 392 & 16.73 & 42.62 \\
\hline $\mathrm{b}$ & 162 & 2.77 & 247 & 21.69 & 386 & 11.35 & 33.22 \\
\hline c & 158 & 4.67 & 248 & 23.02 & 413 & 10.46 & 25.67 \\
\hline d & 149 & 8.37 & 252 & 26.09 & 413 & 10.25 & 18.33 \\
\hline e & 154 & 10.84 & 259 & 27.49 & 414 & 9.45 & 30.55 \\
\hline $\mathrm{f}$ & 152 & 12.07 & 261 & 28.65 & 435 & 9.31 & 24.73 \\
\hline $\mathrm{g}$ & 286 & 66.27 & - & - & - & - & 31.13 \\
\hline
\end{tabular}

In the case of sodium lignosulfonate, the weight loss in the temperature range of $100-150{ }^{\circ} \mathrm{C}$ was due to the rupture of aliphatic hydroxyl groups, carbonyl groups, and $\mathrm{C}-\mathrm{C}$ linkages in the side chains of sodium lignosulfonate. Water and carbon dioxide $\left(\mathrm{CO}_{2}\right)$ were formed in this temperature range. The weight loss at $228{ }^{\circ} \mathrm{C}$ was ascribed to the decomposition of phenolic compounds (aromatic rings, hydroxyl groups, and alkyl groups). The degradation behavior at $392{ }^{\circ} \mathrm{C}$ was ascribed to the thermal degradation of sulfonic groups [36]. The peaks for weight loss above $600{ }^{\circ} \mathrm{C}$ were attributed to decomposition, condensation, and secondary thermal cracking of phenolic compounds [37]. 
As compared to sodium lignosulfonate, the TG-DTG curves of chitosan were simpler. There were only two decomposition stages. The first stage below $100{ }^{\circ} \mathrm{C}$ corresponded to loss of water. Maximum weight loss occurred in the second stage, with its peak at $286{ }^{\circ} \mathrm{C}$, which corresponded to the rupture of intramolecular hydrogen bonds and molecular chains of chitosan [38].

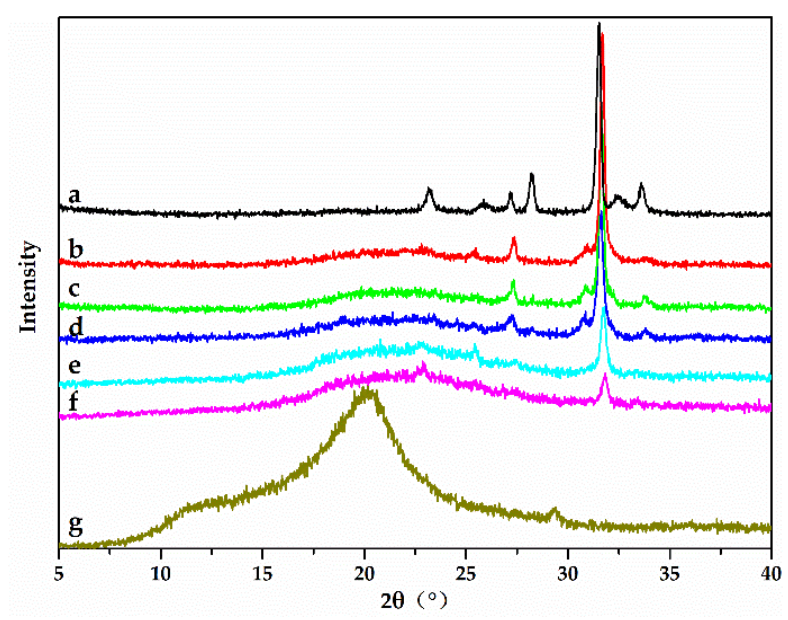

Figure 4. XRD patterns of (a) sodium lignosulfonate, $\mathrm{L} / \mathrm{C}$ with different mass ratios of sodium lignosulfonate to chitosan: (b) 3:1, (c) 2:1, (d) 1:1, (e) 1:2, (f) 1:3, and (g) chitosan.

The weight loss below $100{ }^{\circ} \mathrm{C}$ in L/C corresponded to the loss of water. In the TG-DTG curve of sodium lignosulfonate, the weight loss between $100-150{ }^{\circ} \mathrm{C}$ was due to aliphatic hydroxyl groups, carbonyl groups, and $\mathrm{C}-\mathrm{C}$ linkages in the side chain. Meanwhile, chitosan underwent weight loss slowly and gradually and no distinct weight loss peaks were observed between $100-150{ }^{\circ} \mathrm{C}$. However, the weight loss of $\mathrm{L} / \mathrm{C}$ increased with a decrease in sodium lignosulfonate content between $100-150{ }^{\circ} \mathrm{C}$. This could be due to the reaction between carbonyl groups of the sodium lignosulfonate side chains and amino groups of chitosan that affected the thermal degradation behavior of $\mathrm{L} / \mathrm{C}$ within this temperature range. It could also be due the reaction between the thermal degradation products of side chains in sodium lignosulfonate with chitosan that affected the thermal decomposition of chitosan in this temperature range. A weight loss peak at around $240{ }^{\circ} \mathrm{C}$ in the TG-DTG curves of L/C could be attributed to the overlapping of the peaks at $228^{\circ} \mathrm{C}$ in the TG-DTG curve of sodium lignosulfonate and $286{ }^{\circ} \mathrm{C}$ in the TG-DTG curve of chitosan. The weight loss at around $240{ }^{\circ} \mathrm{C}$ in $\mathrm{L} / \mathrm{C}$ increased and the peak was shifted to higher temperatures $\left(280^{\circ} \mathrm{C}\right)$ with a decrease in the sodium lignosulfonate content. It is noteworthy that chitosan lost most of its weight $\left(66.27 \%\right.$ of its total weight) at $286{ }^{\circ} \mathrm{C}$. In the case of $\mathrm{L} / \mathrm{C}$, although the weight loss in this temperature range increased with increase in chitosan content, the weight loss of $\mathrm{L} / \mathrm{C}$ with a 1:3 mass ratio of sodium lignosulfonate to chitosan only reached $28.65 \%$, which was significantly less than $66.27 \%$. As mentioned above, the weight loss of chitosan within this temperature range was due to the rupture of intramolecular hydrogen bonds and molecular chains. Hence, the reaction between sodium lignosulfonate and chitosan caused a decrease in the numbers of intramolecular hydrogen bonds of chitosan. This further decreased the weight loss of chitosan within this temperature range. The relative increase in weight loss of $\mathrm{L} / \mathrm{C}$ within the temperature range of $100-150{ }^{\circ} \mathrm{C}$ would also result in a relative decrease of the weight loss of $\mathrm{L} / \mathrm{C}$ at around $240{ }^{\circ} \mathrm{C}$. The peak at $392^{\circ} \mathrm{C}$ in TG-DTG curves of sodium lignosulfonate corresponded to weight loss of sulfonic groups as a result of thermal degradation. Compared to sodium lignosulfonate, this peak in the TG-DTG curves of L/C with a 3:1 mass ratio of sodium lignosulfonate to chitosan shifted to lower temperatures. Moreover, the weight loss corresponding to this peak also decreased. The thermal stability of sulfonamide groups that were newly formed in the reaction between sulfonic groups of sodium lignosulfonate and amino groups of chitosan was lower than those of sulfonic groups. Hence, this peak shifted to lower temperatures. With a decrease in the mass ratio of sodium lignosulfonate to 
chitosan from 3:1 to 1:3, this peak shifted to higher temperatures, whereas the weight loss continued decreasing. The numbers of sulfonic groups that reacted with amino groups decreased with a decrease in sodium lignosulfonate content. Moreover, the increasing amount of chitosan blocked the further transfer of heat to the sulfonic groups. Therefore, this peak finally shifted to higher temperatures. A weak weight loss peak between $540-570{ }^{\circ} \mathrm{C}$ appeared in the TG-DTG curve of L/C with a 3:1 mass ratio of sodium lignosulfonate to chitosan. This peak finally could not be seen with a decrease in the sodium lignosulfonate content of $\mathrm{L} / \mathrm{C}$. As for residues beyond $800{ }^{\circ} \mathrm{C}$, most of the $\mathrm{L} / \mathrm{C}$ blends were less than chitosan and sodium lignosulfonate, meaning that chitosan and sodium lignosulfonate were more thermally stable than $\mathrm{L} / \mathrm{C}$ at high temperature.

In summary, the TG-DTG curves of L/C were not simply the summation of the individual TG-DTG curves of chitosan and sodium lignosulfonate. The thermal degradation behaviors of L/C differed with differences in mass ratios of sodium lignosulfonate and chitosan in L/C. This was partly due to the reaction between chitosan and sodium lignosulfonate, which affected their respective thermal degradation behaviors.

\subsection{XRD Analysis}

The XRD patterns of chitosan, sodium lignosulfonate, and L/C are presented in Figure 4. Chitosan showed two major peaks at $10.9^{\circ}$ and $20.1^{\circ}$, which was consistent with the previous studies [22]. Sodium lignosulfonate showed seven major peaks at $23.1^{\circ}, 25.9^{\circ}, 27.2^{\circ}, 28.2^{\circ}, 31.5^{\circ}$, $32.5^{\circ}$, and $33.6^{\circ}$. The peak at $31.5^{\circ}$ was particularly sharp, which was also consistent with previous studies [39].

In the XRD patterns of $\mathrm{L} / \mathrm{C}$, a new weak and broad peak at $22.5^{\circ}$ appeared as the chitosan content increased. In the chitosan/sodium lignosulfonate solution, when chitosan was completely dissolved, the crystal structure disintegrated due to dissolution in acetic acid. The crystal structure of chitosan was also affected by the reaction between chitosan and sodium lignosulfonate. Therefore, two peaks at $10.9^{\circ}$ and $20.1^{\circ}$ disappeared gradually and a new broad peak at $22.5^{\circ}$ appeared slowly, which was in agreement with previous studies [40]. Furthermore, the intensities of peaks at $23.1^{\circ}, 25.9^{\circ}, 28.2^{\circ}, 32.5^{\circ}$, and $33.6^{\circ}$ gradually weakened. This was due to the overlapping of characteristic peaks of sodium lignosulfonate and chitosan.

The peak at $27.2^{\circ}$ in the XRD pattern of sodium lignosulfonate directly disappeared in the XRD pattern of $\mathrm{L} / \mathrm{C}$, which was similar to the changes in peaks at $1119 \mathrm{~cm}^{-1}, 878 \mathrm{~cm}^{-1}$, and $770 \mathrm{~cm}^{-1}$ in the FTIR spectra of L/C. This phenomenon indicated that the disappearance of the peak at $27.2^{\circ}$ in the XRD pattern might be related to a potential chemical reaction between guaiacyl units in sodium lignosulfonate and chitosan. A new peak at $30.5^{\circ}$ appeared in the XRD patterns of L/C with 3:1, 2:1, and 1:1 mass ratios of sodium lignosulfonate and chitosan and its intensity gradually weakened with increasing chitosan amount, which was similar to the change in the peak at $781 \mathrm{~cm}^{-1}$ in the FTIR spectra of L/C. Therefore, there might be a connection between the changes in the peak at $30.5^{\circ}$ in the XRD patterns of $\mathrm{L} / \mathrm{C}$ might and the peak at $781 \mathrm{~cm}^{-1}$ in the FTIR spectra of $\mathrm{L} / \mathrm{C}$. The change in the peak at $30.5^{\circ}$ in the XRD patterns of L/C might further confirm the formation of sulfonamide linkages as a result of the chemical reaction between sulfonic groups of sodium lignosulfonate and amino groups of chitosan, which can be inferred from the change in the peak at $781 \mathrm{~cm}^{-1}$ in the FTIR spectra of L/C. The intensity of the peak at $31.5^{\circ}$ in XRD pattern of $\mathrm{L} / \mathrm{C}$ with 3:1 mass ratio of sodium lignosulfonate to chitosan increased compared to that of pure sodium lignosulfonate. The causes of this requires further study.

From the results of FTIR analysis, TG-DTG analysis, XRD analysis, and previous studies, the chemical structure and synthesis mechanism of L/C could be roughly conjectured (Figure 5). Sodium lignosulfonate is a 3D polymeric network, whereas chitosan is a linear polymer. Sulfonamide and amide linkages were formed by the reaction between sulfonic and carbonyl groups of sodium lignosulfonate with amino groups of chitosan. Hydrogen bonds were also formed between chitosan and sodium lignosulfonate. Therefore, the adhesive transformed into a 3D network structure from the 
original linear structure of chitosan through these linkages and bonds. The guaiacyl units in sodium lignosulfonate also took part in the reaction.

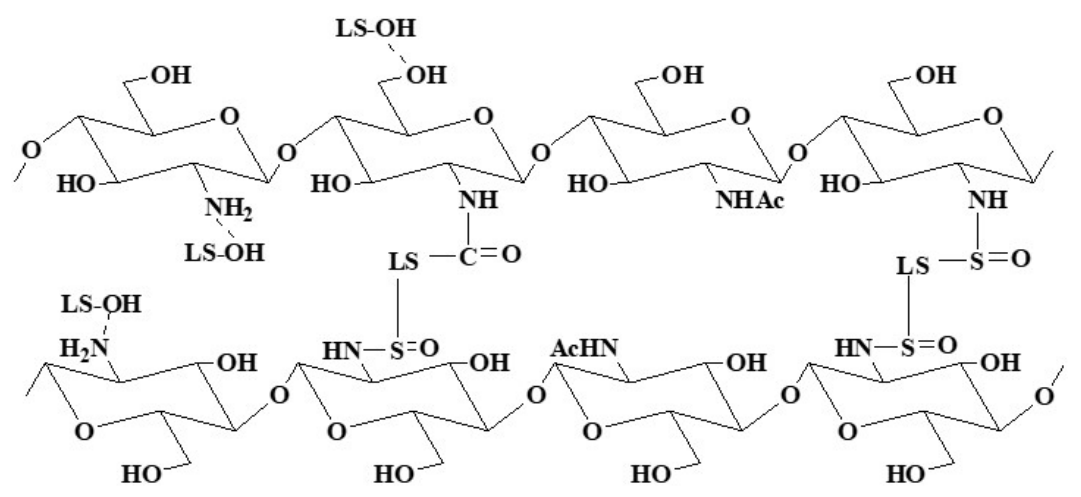

Figure 5. Structure of the L/C (LS refers to sodium lignosulfonate).

\subsection{Bonding Performance Analysis}

It can also be concluded from the results of FTIR analysis, TG-DTG analysis, and XRD analysis that the complexity of the 3D network and the numbers of remaining amino groups varied with different sodium lignosulfonate content in L/C, which would result in different bonding properties of $\mathrm{L} / \mathrm{C}$. In order to further investigate the response of bonding performance to numbers of amino groups, sulfonamide and amide linkages in L/C, the mechanical and dimensional properties of MDFs using $\mathrm{L} / \mathrm{C}$ with different mass ratios of sodium lignosulfonate to chitosan as adhesives were determined.

The mechanical and dimensional properties of MDFs L/C with different mass ratios of sodium lignosulfonate to chitosan as adhesives are shown in Figure 6. When the mass ratio of sodium lignosulfonate and chitosan was 1:0 or 0:1-in other words, when pure sodium lignosulfonate or pure chitosan was used as the adhesive-the IB, MOE, MOR, and TS values of MDF were $0.32 \mathrm{MPa}$, 996.95 $\mathrm{MPa}, 10.14 \mathrm{MPa}, 40.88 \%$, or $1.21 \mathrm{MPa}, 3631.1 \mathrm{MPa}, 41.96 \mathrm{MPa}, 12.73 \%$, respectively. Therefore, the mechanical and dimensional properties of MDF were better when pure chitosan was used as the adhesive than when pure sodium lignosulfonate was used. This indicated that pure chitosan was more suitable as MDF adhesive than sodium lignosulfonate.

However, when the mass ratio of sodium lignosulfonate to chitosan increased from 0:1 to 1:3, the IB, MOE, and MOR of MDF improved, signifying that the mechanical properties of MDF improved when suitable amounts of sodium lignosulfonate were used to replace a portion of chitosan. It could be inferred according to the deacetylation degree of chitosan, sulfonation degree of lignosulfonate, and results of FTIR analysis, TG-DTG analysis, and XRD analysis that when the mass ratio of sodium lignosulfonate to chitosan was 1:3 in L/C, a 3D polymeric network formed with a lot of remaining amino groups. Our earlier work demonstrated that amino groups in chitosan played an important role in bonding with wood fibers [41]. Sodium lignosulfonate could also weakly adhere to wood fibers. Therefore, the mechanical properties of MDFs using L/C with a 1:3 mass ratio of sodium lignosulfonate to chitosan as the adhesive increased compared to MDFs using pure chitosan as the adhesive. With further addition of sodium lignosulfonate in the adhesive, the mechanical properties of MDF did not continue to improve, but instead declined. This phenomenon indicated that a further increase in the complexity of the 3D network and reduction in amino groups which could adhere to wood fibers strongly would not increase the bonding performance of $\mathrm{L} / \mathrm{C}$. However, even when the mass ratio of sodium lignosulfonate to chitosan increased further to 3:1, the mechanical properties of this MDF were similar to that of MDF with pure chitosan as the adhesive, indicating that the 3D polymeric network of L/C also played an important role in the mechanical properties of MDFs. The mechanical properties of MDFs deteriorated drastically when the mass ratio of sodium lignosulfonate to chitosan further increased to 1:0-in other words, the MDF was prepared with pure sodium lignosulfonate 
as the adhesive. This indicated that sodium lignosulfonate itself was not particularly suitable as MDF adhesive.

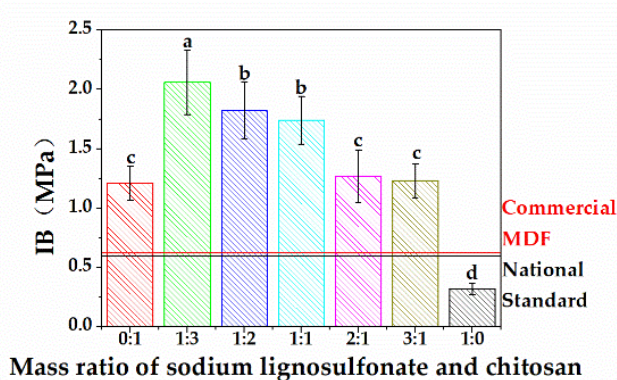

(A)

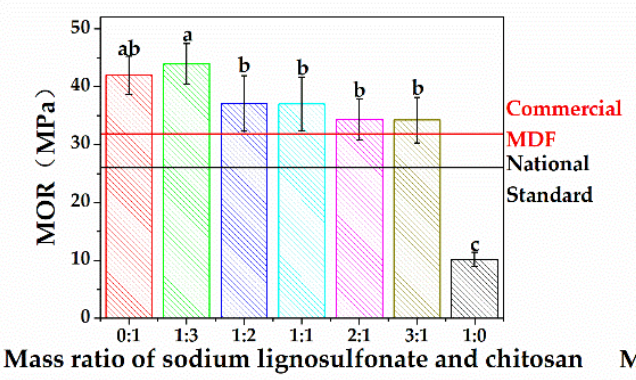

(C)

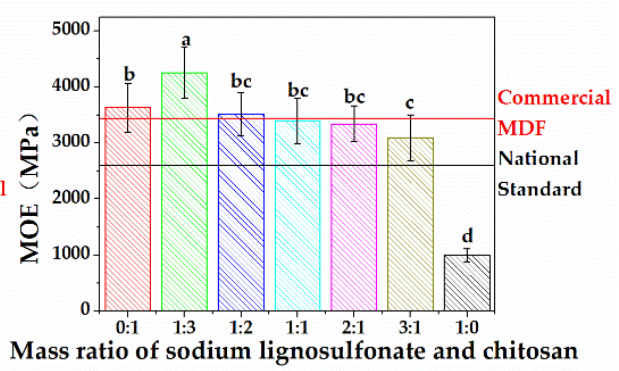

(B)

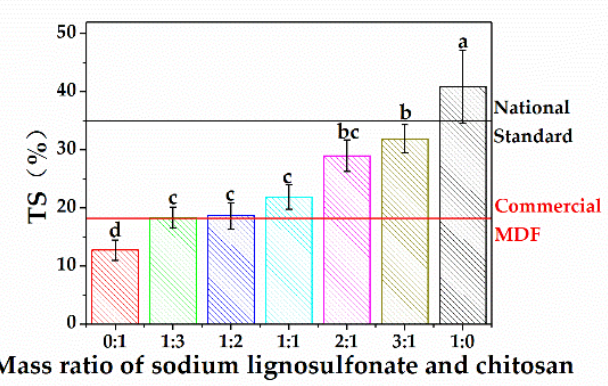

(D)

Figure 6. (A) Influence of sodium lignosulfonate content on internal bond strength (IB); (B) Influence of sodium lignosulfonate content on modulus of elasticity (MOE); (C) Influence of sodium lignosulfonate content on modulus of rupture (MOR); (D) Influence of sodium lignosulfonate content on thickness swell (TS).

Compared to pure chitosan as the adhesive, when the mass ratio of sodium lignosulfonate to chitosan in the adhesive was 1:3, the TS of MDF showed a slight increase, indicating a decline in the dimensional property. The trends in the dimensional property were different to the trends in the mechanical properties. This indicated that the dimensional properties of MDFs did not improve despite reaction between sodium lignosulfonate and chitosan, but decreased it due to the hydrophilic nature of sodium lignosulfonate.

In summary, the mechanical properties of MDFs were closely related to the 3D polymeric network and amino groups of $\mathrm{L} / \mathrm{C}$. A proper 3D network and large numbers of amino groups were found to improve the mechanical performance of MDFs. The dimensional properties decreased as a result of the addition of sodium lignosulfonate despite the reaction of sodium lignosulfonate and chitosan. The mechanical properties of MDFs using L/C with 1:3 and 1:2 mass ratios of sodium lignosulfonate to chitosan as adhesives were significantly superior to those of the commercial panel, while their dimensional properties were nearly the same. The mechanical and dimensional properties of MDFs using $\mathrm{L} / \mathrm{C}$ as adhesives were complied with the Chinese national standards for MDF panels (CNS, GB/T 11718-2009, MDF-GP REG).

\section{Conclusions}

The synthesis mechanism and the response of bonding performance to synthesis mechanism of $\mathrm{L} / \mathrm{C}$ were investigated based on analysis of the chemical structure, thermal stability, and crystalline structure of $\mathrm{L} / \mathrm{C}$ and mechanical and dimensional properties of MDFs. The results revealed that a 3D polymeric network formed in L/C because of hydrogen linkages among hydroxyl groups in sodium 
lignosulfonate and hydroxyl and amino groups in chitosan, amide linkages resulted from reaction between carbonyl groups in sodium lignosulfonate and amino groups in chitosan, and sulfonamide linkages originated from reaction between sulfonic groups in sodium lignosulfonate and amino groups in chitosan. The mechanical performance of MDFs was closely related to the 3D network and remaining amino groups, while the addition of sodium lignosulfonate negatively affected the dimensional property of MDFs. The mechanical properties of MDFs with 1:3 and 1:2 mass ratios of sodium lignosulfonate to chitosan were superior to those of the commercial panel, while their dimensional properties were on the same level. The mechanical and dimensional properties of MDFs using $\mathrm{L} / \mathrm{C}$ as adhesives all met the requirement of the Chinese national standard for MDFs (CNS, GB/T11718-2009, MDF-GP REG). The synthesis mechanism of $\mathrm{L} / \mathrm{C}$ and the response of bonding performance to the synthesis mechanism could provide a theoretical foundation for further studies that would focus on further cutting the cost of the adhesives, improving the dimensional performance of the MDF, optimizing the hot-pressing process, and exploring the bonding mechanism between the adhesives and MDF.

Author Contributions: Conceptualization, L.Z.; Formal analysis, X.J.; Funding acquisition, M.G.; Investigation, X.J. and M.G.; Methodology, X.J. and W.D.; Supervision, M.G., L.Z. and H.W.; Validation, W.D.; Visualization, L.Z.; Writing —original draft, X.J.; Writing—review \& editing, X.J. and H.W. All authors have read and agreed to the published version of the manuscript.

Funding: This research was funded by the Natural Science Basic Research Plan in Shaanxi Province of China (2020JQ-260) and the Ph. D. Start-up Fund of Northwest A\&F University (2452019009).

Conflicts of Interest: The authors declare no conflict of interest.

\section{References}

1. Heinrich, L.A. Future opportunities for bio-based adhesives-advantages beyond renewability. Green Chem. 2019, 21, 1866-1888. [CrossRef]

2. Kumar, R.; Choudhary, V.; Mishra, S.; Varma, I.K.; Mattiason, B. Adhesives and plastics based on soy protein products. Ind. Crop. Prod. 2002, 16, 155-172. [CrossRef]

3. Imam, S.H.; Gordon, S.H.; Mao, L.; Chen, L. Environmentally friendly wood adhesive from a renewable plant polymer: Characteristics and optimization. Polym. Degrad. Stab. 2001, 73, 529-533. [CrossRef]

4. Oh, M.; Ma, Q.; Simsek, S.; Bajwa, D.; Jiang, L. Comparative study of zein- and gluten-based wood adhesives containing cellulose nanofibers and crosslinking agent for improved bond strength. Int. J. Adhes. Adhes. 2019, 92, 44-57. [CrossRef]

5. Moslemi, A.; Koohi, M.Z.; Behzad, T.; Pizzi, A. Addition of cellulose nanofibers extracted from rice straw to urea formaldehyde resin; effect on the adhesive characteristics and medium density fiberboard properties. Int. J. Adhes. Adhes. 2020, 99. [CrossRef]

6. Pillai, C.K.S.; Paul, W.; Sharma, C.P. Chitin and chitosan polymers: Chemistry, solubility and fiber formation. Prog. Polym. Sci. 2009, 34, 641-678. [CrossRef]

7. Ali, A.; Ahmed, S. A review on chitosan and its nanocomposites in drug delivery. Int. J. Biol. Macromol. 2018, 109, 273-286. [CrossRef]

8. Arima, Y.; Iwata, H. Effect of wettability and surface functional groups on protein adsorption and cell adhesion using well-defined mixed self-assembled monolayers. Biomaterials 2007, 28, 3074-3082. [CrossRef]

9. Xu, Y.X.; Kim, K.M.; Hanna, M.A.; Nag, D. Chitosan-starch composite film: Preparation and characterization. Ind. Crop. Prod. 2005, 21, 185-192. [CrossRef]

10. Vo, D.-T.; Lee, C.-K. Antimicrobial sponge prepared by hydrophobically modified chitosan for bacteria removal. Carbohydr. Polym. 2018, 187, 1-7. [CrossRef]

11. Ferreira, A.M.; Pereira, J.; Almeida, M.; Ferra, J.; Paiva, N.; Martins, J.; Magalhães, F.D.; Carvalho, L.H. Low-cost natural binder for particleboards production: Study of manufacture conditions and stability. Int. J. Adhes. Adhes. 2019, 93, 102325. [CrossRef]

12. Pang, H.W.; Zhao, S.J.; Mo, L.T.; Wang, Z.; Zhang, W.; Huang, A.M.; Zhang, S.F.; Li, J.Z. Mussel-inspired bio-based water-resistant soy adhesives with low-cost dopamine analogue-modified silkworm silk Fiber. J. Appl. Polym. Sci. 2020, 137. [CrossRef] 
13. Santiago-Medina, F.; Foyer, G.; Pizzi, A.; Caillol, S.; Delmotte, L. Lignin-derived non-toxic aldehydes for ecofriendly tannin adhesives for wood panels. Int. J. Adhes. Adhes. 2016, 70, 239-248. [CrossRef]

14. Yelle, D.J. Solution-state NMR analysis of hydroxymethylated resorcinol cured in the presence of crude milled-wood lignin from Acer saccharum. J. Appl. Polym. Sci. 2017, 134. [CrossRef]

15. Pradyawong, S.; Qi, G.Y.; Li, N.B.; Sun, X.Z.S.; Wang, D.H. Adhesion properties of soy protein adhesives enhanced by biomass lignin. Int. J. Adhes. Adhes. 2017, 75, 66-73. [CrossRef]

16. Hemmila, V.; Adamopoulos, S.; Hosseinpourpia, R.; Ahmed, S.A. Ammonium Lignosulfonate Adhesives for Particleboards with pMDI and Furfuryl Alcohol as Crosslinkers. Polymers 2019, 11, 1633. [CrossRef]

17. Gadhave, R.V.; Kasbe, P.S.; Mahanwar, P.A.; Gadekar, P.T. Synthesis and characterization of lignin-polyurethane based wood adhesive. Int. J. Adhes. Adhes. 2019, 95. [CrossRef]

18. Sohni, S.; Hashim, R.; Nidaullah, H.; Lamaming, J.; Sulaiman, O. Chitosan/nano-lignin based composite as a new sorbent for enhanced removal of dye pollution from aqueous solutions. Int. J. Biol. Macromol. 2019, 132, 1304-1317. [CrossRef]

19. Jaganathan, G.; Manivannan, K.; Lakshmanan, S.; Sithique, M.A. Fabrication and characterization of Artocarpus heterophyllus waste derived lignin added chitosan biocomposites for wound dressing application. Sustain. Chem. Pharm. 2018, 10, 27-32. [CrossRef]

20. Zou, T.; Sipponen, M.H.; Osterberg, M. Natural Shape-Retaining Microcapsules with Shells Made of Chitosan-Coated Colloidal Lignin Particles. Front. Chem. 2019, 7. [CrossRef]

21. Xu, J.D.; Niu, Y.S.; Yue, P.P.; Hu, Y.J.; Bian, J.; Li, M.F.; Peng, F.; Sun, R.C. Composite Film Based on Pulping Industry Waste and Chitosan for Food Packaging. Materials 2018, 11, 2264. [CrossRef] [PubMed]

22. Ji, X.D.; Dong, Y.; Yuan, B.N.; Li, B.; Guo, M.H. Influence of glutaraldehyde on the performance of a lignosulfonate/chitosan-based medium density fiberboard adhesive. J. Appl. Polym. Sci. 2018, 135. [CrossRef]

23. Ji, X.D.; Guo, M.H. Preparation and properties of a chitosan-lignin wood adhesive. Int. J. Adhes. Adhes. 2018, 82, 8-13. [CrossRef]

24. Pawlak, A.; Mucha, M. Thermogravimetric and FTIR studies of chitosan blends. Thermochim. Acta 2003, 396, 153-166. [CrossRef]

25. Lawrie, G.; Keen, I.; Drew, B.; Chandler-Temple, A.; Rintoul, L.; Fredericks, P.; Grøndahl, L. Interactions between Alginate and Chitosan Biopolymers Characterized Using FTIR and XPS. Biomacromolecules 2007, 8, 2533-2541. [CrossRef] [PubMed]

26. Queiroz, M.F.; Melo, K.R.T.; Sabry, D.A.; Sassaki, G.L.; Rocha, H.A.O. Does the Use of Chitosan Contribute to Oxalate Kidney Stone Formation? Mar. Drugs 2015, 13, 141-158. [CrossRef]

27. Li, B.; Shan, C.L.; Zhou, Q.; Fang, Y.; Wang, Y.L.; Xu, F.; Han, L.R.; Ibrahim, M.; Guo, L.B.; Xie, G.L.; et al. Synthesis, Characterization, and Antibacterial Activity of Cross-Linked Chitosan-Glutaraldehyde. Mar. Drugs 2013, 11, 1534-1552. [CrossRef]

28. Wysokowski, M.; Klapiszewski, L.; Moszynski, D.; Bartczak, P.; Szatkowski, T.; Majchrzak, I.; Siwinska-Stefanska, K.; Bazhenov, V.V.; Jesionowski, T. Modification of Chitin with Kraft Lignin and Development of New Biosorbents for Removal of Cadmium(II) and Nickel(II) Ions. Mar. Drugs 2014, 12, 2245-2268. [CrossRef]

29. Geng, J.; Gu, F.; Chang, J. Fabrication of magnetic lignosulfonate using ultrasonic-assisted in situ synthesis for efficient removal of $\mathrm{Cr}(\mathrm{VI})$ and Rhodamine B from wastewater. J. Hazard. Mater. 2019, 375, 174-181. [CrossRef]

30. Yang, J.; Wu, J.-X.; Lü, Q.-F.; Lin, T.-T. Facile Preparation of Lignosulfonate-Graphene Oxide-Polyaniline Ternary Nanocomposite as an Effective Adsorbent for Pb(II) Ions. ACS Sustain. Chem. Eng. 2014, 2, 1203-1211. [CrossRef]

31. Vijay, A.; Sathyanarayana, D.N. Ab initio study of the vibrational assignment and force field of thiosemicarbazide-d0 and -d5. Spectrochim. Acta A 1992, 48, 1601-1609. [CrossRef]

32. Sengupta, P.K.; Krimm, S. Vibrational analysis of peptides, polypeptides, and proteins. XXXII. $\alpha$-Poly(L-glutamic acid). Biopolymers 1985, 24, 1479-1491. [CrossRef] [PubMed]

33. Sarojini, K.; Krishnan, H.; Kanakam, C.C.; Muthu, S. Synthesis, structural, spectroscopic studies, NBO analysis, NLO and HOMO-LUMO of 4-methyl-N-(3-nitrophenyl)benzene sulfonamide with experimental and theoretical approaches. Spectrochim. Acta A 2013, 108, 159-170. [CrossRef] [PubMed] 
34. Kaushal, A.M.; Chakraborti, A.K.; Bansal, A.K. FTIR Studies on Differential Intermolecular Association in Crystalline and Amorphous States of Structurally Related Non-Steroidal Anti-Inflammatory Drugs. Mol. Pharmaceut. 2008, 5, 937-945. [CrossRef]

35. Álvarez, R.M.S.; Cutín, E.H.; Mack, H.-G.; Romano, R.M.; Della Védova, C.O. Vibrational Spectra of Trifluoromethanesulfonyl Isocyanate, $\mathrm{CF}_{3} \mathrm{SO}_{2} \mathrm{NCO}$. J. Raman Spectrosc. 1997, 28, 277-281. [CrossRef]

36. Lü, Q.-F.; He, Z.-W.; Zhang, J.-Y.; Lin, Q. Preparation and properties of nitrogen-containing hollow carbon nanospheres by pyrolysis of polyaniline-lignosulfonate composites. J. Anal. Appl. Pyrolysis 2011, 92, 152-157. [CrossRef]

37. Ye, D.-Z.; Jiang, X.-c.; Xia, C.; Liu, L.; Zhang, X. Graft polymers of eucalyptus lignosulfonate calcium with acrylic acid: Synthesis and characterization. Carbohydr. Polym. 2012, 89, 876-882. [CrossRef]

38. Pereira, L.A.; da Silva Reis, L.; Batista, F.A.; Mendes, A.N.; Osajima, J.A.; Silva-Filho, E.C. Biological properties of chitosan derivatives associated with the ceftazidime drug. Carbohydr. Polym. 2019, 222, 115002. [CrossRef]

39. Hasegawa, M.; Isogai, A.; Onabe, F. Preparation of low-molecular-weight chitosan using phosphoric acid. Carbohydr. Polym. 1993, 20, 279-283. [CrossRef]

40. Pandey, R.P.; Rasool, K.; Rasheed, P.A.; Gomez, T.; Pasha, M.; Mansour, S.A.; Lee, O.-S.; Mahmoud, K.A. One-step synthesis of an antimicrobial framework based on covalently cross-linked chitosan/lignosulfonate (CS@LS) nanospheres. Green Chem. 2020, 22, 678-687. [CrossRef]

41. Ji, X.D.; Dong, Y.; Yu, R.D.; Du, W.; Gu, X.; Guo, M.H. Simple production of medium density fiberboards (MDF) reinforced with chitosan. Holzforschung 2018, 72, 275-281. [CrossRef]

Publisher's Note: MDPI stays neutral with regard to jurisdictional claims in published maps and institutional affiliations.

(C) 2020 by the authors. Licensee MDPI, Basel, Switzerland. This article is an open access article distributed under the terms and conditions of the Creative Commons Attribution (CC BY) license (http://creativecommons.org/licenses/by/4.0/). 